\title{
Analysis of MR Imaging of Wrists in Female Patients with Carpal Tunnel Syndrome and Healthy Controls
}

\author{
Análisis de Imágenes de RM de las Muñecas en Pacientes Mujeres \\ con Síndrome del Túnel Carpiano y Controles Sanos
}

\author{
"Özlen Karabulut; "Mehmet Cudi Tuncer; **Zülfü Karabulut \& ${ }^{* * *}$ Ebru Güzel
}

KARABULUT, Ö.; TUNCER, M. C.; KARABULUT, Z. \& GÜZEL, E. Analysis of MR imaging of wrists in female patients with carpal tunnel syndrome and healthy controls. Int. J. Morphol., 27(3):791-800, 2009.

SUMMARY: The objective of this study was to evaluate morphological changes of the median nerve in patients with carpal tunnel syndrome (CTS) and healthy controls, to correlate the MRI findings of wrists. This study compared not only morphological changes of the median nerve and also displayed descriptively structures in carpal tunnel between patients diagnosed with idopathic CTS and healthy controls. Our study involved 60 hand, 30 of hand were evaluated diagnosed with idiopathic CTS and 30 hand as healthy controls bilaterally. Two provocative tests (Phalen's and Tinel's test) were performed on each hand for both the patient group (60 wrist) and the control group (60 wrist). With regard to Phalen and Tinel's test results, 24 and 26 wrists were excluded from patient and control groups respectively. Totally 70 wrists were evaluated, and in terms of cross-sectional area of median nerve at the level of distal radioulnar joint, pisiform bone and the hook of hamate bone by MRI in the patient and control groups. In addition to evaluation of crosssectional area of median nerve, we determined signal intensity of wrists and different localization of the median nerve in the carpal tunnel. Cross-sectional area of the median nerve measured by wrist magnetic resonance at the level of metacarpal bones and signal intensity of wrists may be considered as a valuable indicator to determine patients referred with idiopathic CTS.

KEY WORDS: MR imaging; Carpal tunnel syndrome; Cross-sectional area; Signal intensity; Median nerve.

\section{INTRODUCTION}

Carpal Tunnel Syndrome (CTS) is one of the most common entrapment neuropathy in upper extremity. Since the cause of CTS is median nerve neuropathy with an unclear localization of entrapment and the nerve tends to be in variable localizations.

The evaluation of peripheral nerve lesions of the upper extremities has traditionally relied on information from an accurate clinical history, a thorough physical examination and electro-diagnostic testing. In most of the patients suffer severely a pain from the etiology of the underlying nerve injury (Andreisek et al., 2008). Recently, most studies have pointed that MRI findings in various areas with related to median nerve and other peripheral nerves disorders in upper extremity peripheral neuropathies (Andreisek et al.; Kim et al., 2007; Grant et al., 2001; Taussaint et al., 2008; Hof et al., 2008; Amrami et al., 2008).
Imaging may provide important information in entrapment neuropathies, particularly in cases of equivocal electrophysiologic studies. Improvements in magnetic resonance imaging have allowed visualization of the nerve as it travels in the upper extremity. MRI is also helpful in ruling out other causes of nerve compression, such as tumors (Spratt et al., 2002; Taussaint et al.).

The normal carpal tunnel anatomy is accurately delineated on MR imaging (Zeiss et al., 1989; Maurer et al., 2000; Middleton et al., 1987). The anterior boundary of the carpal tunnel is the flexor retinaculum, also known as the transverse carpal ligament, which appears as a broad lowsignal intensity structure that extends from the hook of hamate bone to the scaphoid and trapezium tubercles. The posterior boundary is formed by the deep palmar carpal

* Department of Anatomy, Faculty of Medicine, Dicle University, 21280, Diyarbakır, Turkey.

** Department of Physical Medicine, Özel Veni Vidi Hospital, 21100, Diyarbakır, Turkey.

**** Department of Radiology, Özel Veni Vidi Hospital, 21100, Diyarbakır, Turkey. 
ligaments and the carpal bones. Because of the rigidity of the boundaries of the carpal tunnel, any process that either increases the volume of the contents of the tunnel or decreases the size of the tunnel can result in symptoms. The median nerve is located in the superficial radial portion of the canal, immediately deep to the flexor retinaculum.

Morphologically, it typically is round or flat, and on MR imaging it appears intermediate in signal intensity. It is constant in caliber throughout the carpal canal, but its location or position varies with wrist flexion or extension; flexion can produce anatomic crowding in the canal (Zeiss et al., 1992; Mesgarzadeh et al., 1989a). The axial plane is the most optimal imaging plane for evaluating the contents of the carpal tunnel.

The carpal tunnel is a space bordered by the carpal bones and flexor retinaculum. The space is approximately 6 $\mathrm{cm}$ in length from the wrist to the mid-palm. In addition to the median nerve, eight tendons of flexor digitorum profundus and flexor digitorum superficialis and one flexor pollicis longus tendon pass through this space. The flexor retinaculum is approximately $3 \mathrm{~cm}$ to $4 \mathrm{~cm}$ wide and $2.5 \mathrm{~cm}$ to $3.5 \mathrm{~mm}$ in thickness. It is attached to scaphoid tubercle and the crest of the trapezium on the radial side and to the pisiform and the hook of hamate bone on the ulnar side. On its radial side, the flexor retinaculum splits into two layers to envelop the flexor carpi radialis tendon. The median nerve courses superficial to the flexor digitorum superficialis (fds) muscle proximal to the carpal tunnel and parallel to the second and third fds tendons within the carpal tunnel (Sallomi et al., 1998; Omer, 1992). In the palm, it gives off five branches. The radial branch is the motor nerve innervating the thenar muscles, and the remaining four branches are sensory branches of the first, second, third, and the radial half of the fourth digit (Shuman et al., 1987) (Figs. 1A and 1B).

Many authors have used to different visualization technics to demonstrate median nerve in carpal tunnel such as MRI (Kim et al.; Deryani et al., 2003; Grant et al.; Bone'1 et al., 2001; Keberle et al., 2000; Monagle et al., 1999; Kleindienst et al., 1998; Amrami et al.; Brahme et al., 1997; Allmann et al., 1997; Sugimoto et al., 1994; Andreisek et $a l$.), diffusion tensor imaging and tractography, and sonography with compare to MR and CT scans (Buchberger et al., 1992; Propeck et al., 2000).

The purpose of our paper is to investigate MRI morphological findings in a series of female patients with idiopathic CTS. We assessed only female because idiopathic CTS is more often seen in female than man (Hurst et al., 1985; Phalen, 1972; Treaster \& Burr, 2004). And, we also appraised the correlations MRI parameters between patient and control groups.

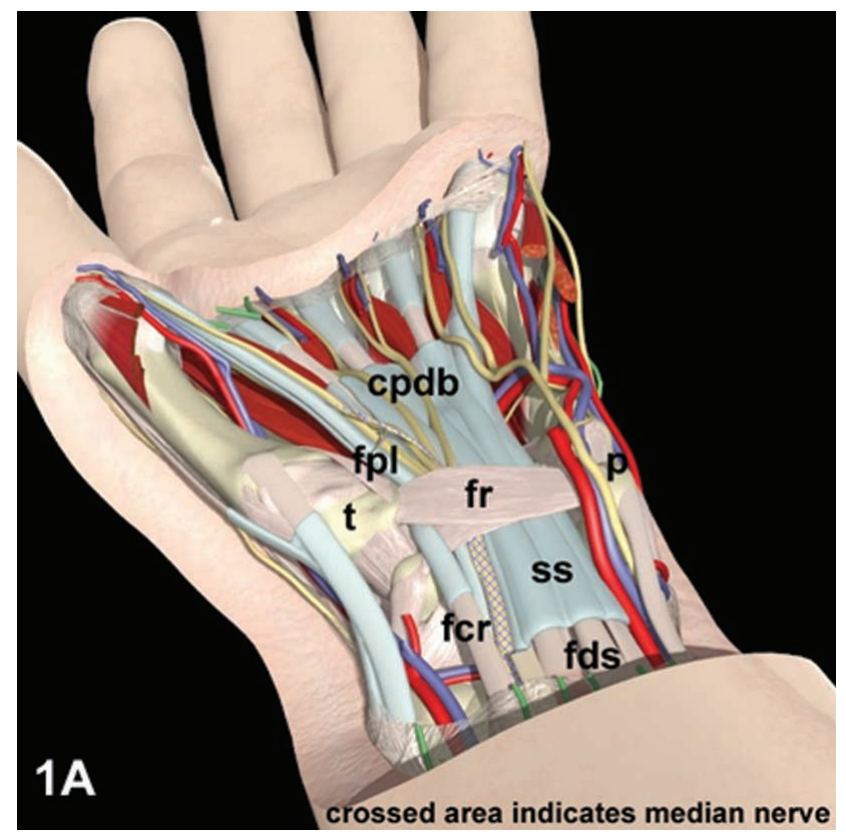

Fig. 1A. Gross anatomy of the carpal tunnel (permission by Primal Pictures 3D Anatomy).

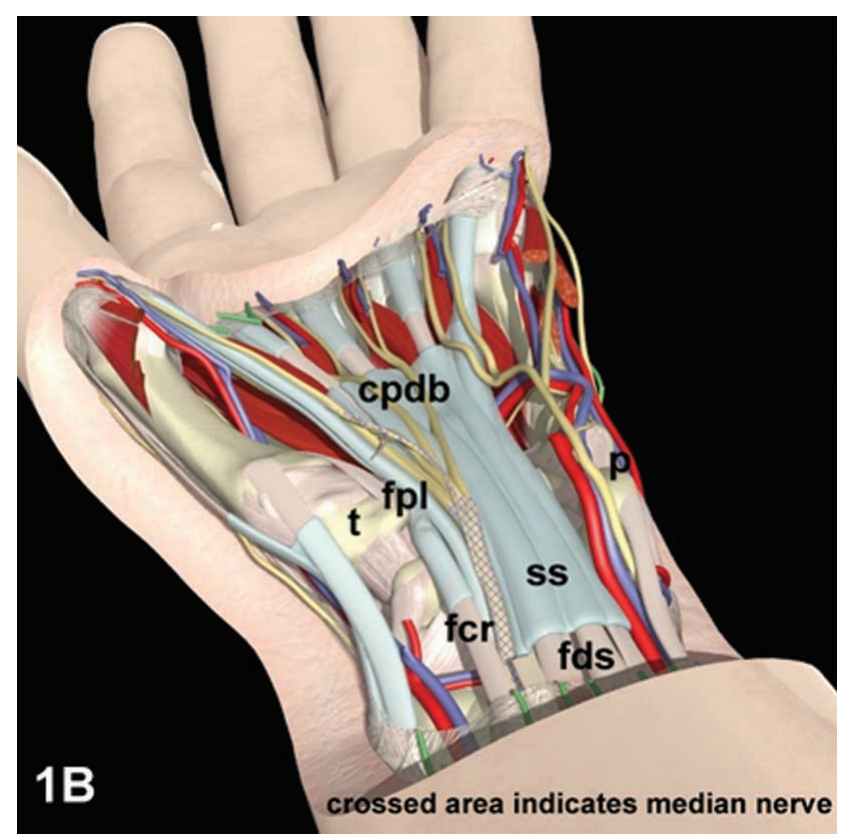

Fig. 1B. Gross anatomy of the carpal tunnel (the flexor retinaculum is removed; permission by Primal Pictures 3D Anatomy). fr: flexor retinaculum, t: trapezium bone, p: pisiform bone, ss: common synovial sheath of the digital flexors, fds: tendons of flexor digitorum superficialis muscle, fcr: tendon of flexor carpi radialis muscle, fpl: tendon of flexor pollicis longus, cpdb: common palmar digital branches of the median nerve.

\section{MATERIAL AND METHOD}

Patients. Two women groups of subjects were included in 
the study, all of whom underwent MR imaging. A group of 30 patients with clinical findings of idiopathic CTS and a control group of 30 unaffected patients consisted of hospital employees, all with no history of nerve entrapment in the proximal or distal arm, referred to the MR unit primarily for indications other than CTS were scanned in a dedicated 1.5 T MR scanner (Magnetom Siemens Symphony, Germany), including obtaining a written consent from the patient and control groups.

MR Protocol. The imaging protocol included axial T1weighted (TR $3070 \mathrm{~ms}$, TE $80 \mathrm{~ms}$ ), coronal T1-weighted (TR $414 \mathrm{~ms}$, TE $22 \mathrm{~ms}$ ), short inversion recovery (STIR) in axial sections (TR $4880 \mathrm{~ms}$, TE $60 \mathrm{~ms}$ ) and coronal T2-weighted short inversion recovery (STIR; TR 4880 $\mathrm{ms}$, TE $60 \mathrm{~ms}$ ) at the level of the distal radio-ulnar joint, the pisiform bone, and the hamate bone. During the imaging with a 1,5 Tesla MR, the participants were in prone position with the involved arm in supine position and the elbow in slight flexion. T1 weighted axial sections and T2 weighted coronal sections were chosen for the examination. The field of view was $160 \times 160$ $\mathrm{mm}$ for all scans. The slice thickness was $3 \mathrm{~mm}$.

Evaluation. All examinations were evaluated by one radiologist: senior staff radiologist with $>4$ years of experience in reading films and experience with the dedicated 1.5 T MR. Radiologist was blinded to the clinical information of the patients or test persons.

Normal anatomic representation of the median nerve and other stuructures in carpal tunnel were represented both schematic and MR scans in axial sections. (Figs. 2A and 2B). Pathologic findings were represented very well such as interposition of the median nerve in MR scans. The focus was especially on the level of distal radio-ulnar joint and the pisiform bone, where enlargement of the nerve is usually encountered in CTS, and on the hamate bone level, where flattening of the nerve may occur. In addition to cross-sectional area of the median nerve, signal intensity of wrist and variational localization of the median nerve were evaluated statistically.

Statistical analysis. The results were compared and evaluated statistically using Independent Samples t-Test and Paired Samples t-Test. P values inferior to 0.05 were considered statistically significant.

Clinical data. The anamnesis of the patient which consists of burning wrist pain, increasing pain with repeated wrist actions, paresthesia in the palm points at idiopathic CTS diagnosis.
In physical examination, two common methods are valuable. Parestesia existing in the median nerve locality with elegant tapping over the carpal tunnel is the Positive Tinel's Sign. Appearing of parestesia with passive wrist flexion nearly for a minute represants Positive Phalen's Test (Jarvik et al., 2002). We performed these provocative tests bilaterally. The

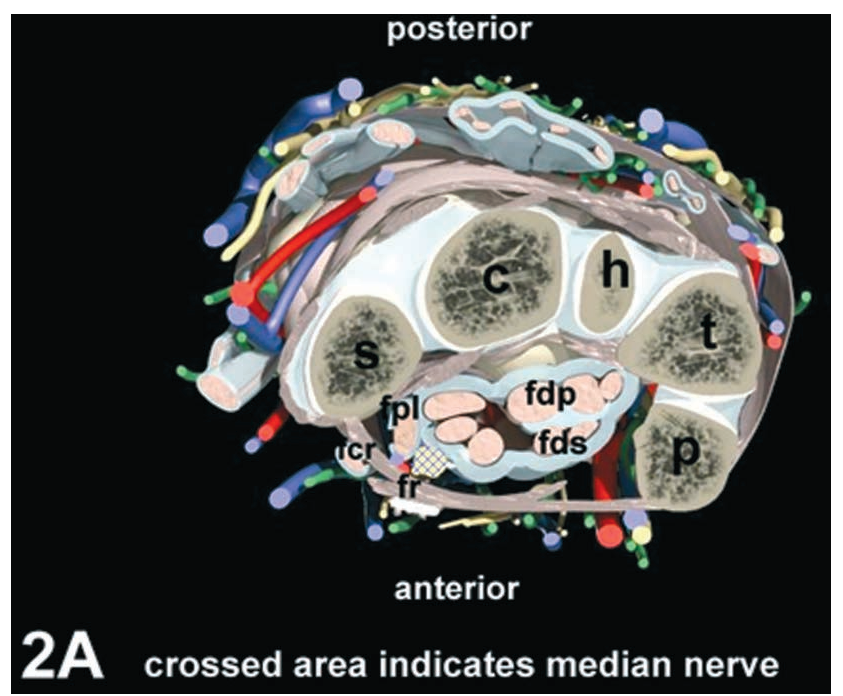

Fig. 2A. Schematic section of carpal tunnel in axial model at the level of metacarpal bones (permission by Primal Pictures 3D Anatomy).

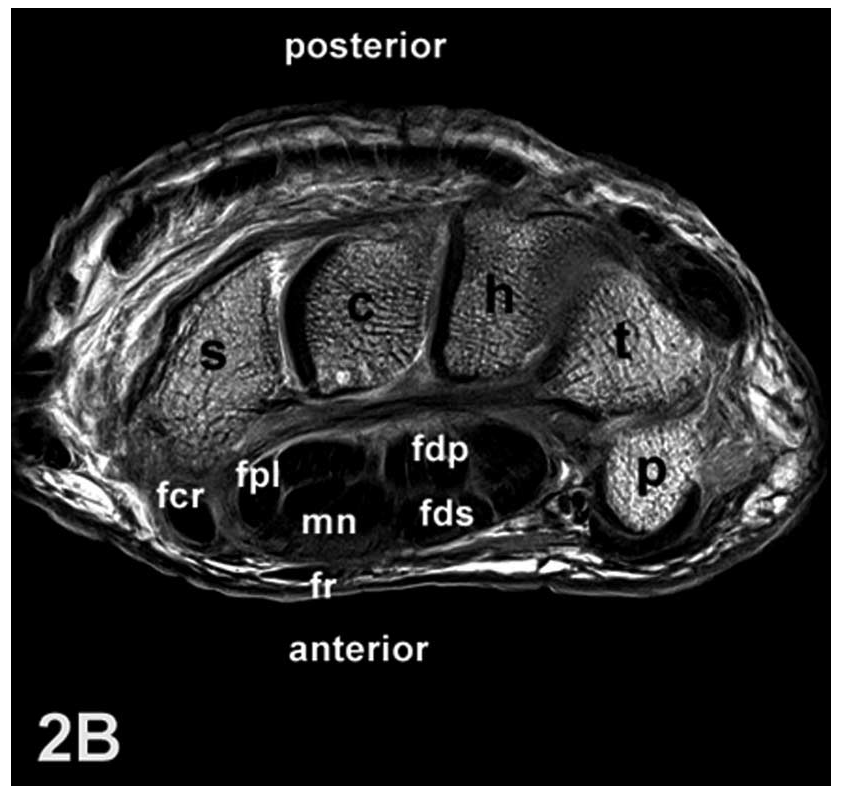

Fig. 2B. Normal anatomic localization of the median nerve in the carpal tunnel. Axial T1-weighted images of the median nerve MR with normal size at the level of metacarpal bones (permission by Primal Pictures 3D Anatomy). s: scaphoid bone, c: capitate bone, $\mathrm{h}$ : hamate bone, $\mathrm{t}$ : triquetrum bone, $\mathrm{p}$ : pisiform bone, fcr: tendon of flexor carpi radialis muscle, fpl: tendon of flexor pollicis longus, fdp: tendons of flexor digitorum profundus muscle, fds: tendons of flexor digitorum superficialis muscle, mn: median nerve, fr: flexor retinaculum. 
results of Tinel's sign and Phalen's test were abstracted for each patient. Tinel's sign was scored as positive if the attending physician had indicated in the patient's chart that tapping on the median nerve produced tingling in the median nerve distribution; otherwise, it was negative. Phalen's test was scored positive if wrist flexion produced numbness or tingling in the median nerve distribution within 60 seconds.

\section{RESULTS}

The mean age of the CTS diagnosed patient group was $47.33 \pm 12.29$ and the mean age of the control group was $42.25 \pm 10.30$. There was no significant difference in terms of age between two groups ( $\mathrm{p}>0.05)$.

With regard to Phalen and Tinel's test results, 24 and 26 wrists were excluded from the patient and control groups respectively. Table I shows the number of positive and negative results of the Phalen test and the Tinel test in the CTS group as well as in the control group. Sensitivity and specificity for the Phalen test were respectively 90 and $80 \%$ and for the Tinel test 70 and $76.6 \%$. Totally, 36 wrists in the patient group and 34 wrists in the control group were evaluated in according to cross-sectional area and signal intensity.

We determined an increase in cross-sectional area at the level of distal radio-ulnar joint and pisiform bone. However, there was a statistically significant difference between them in terms of cross-sectional area at the level of distal radio-ulnar joint $\left(14.37 \pm 2.97 \mathrm{~mm}^{2}\right.$ in patient group; $11.62 \pm 2.01 \mathrm{~mm}^{2}$ in control group, $\mathrm{p}<0.005)$ and at the level of pisiform bone $(15.94 \pm$
$3.05 \mathrm{~mm}^{2}$ in patient group; $13.45 \pm 4.23 \mathrm{~mm}^{2}$ in control group, $\mathrm{p}<0.05$ ) (Table II). When we evaluated cross-sectional area of the median nerve at the level of the hook of hamate bone. There was not a increase in cross-sectional area of the median nerve at the level of the hook of hamate bone. No statistically significant difference was observed at the level of the hook of hamate bone $\left(15.65 \pm 2.89 \mathrm{~mm}^{2}\right.$ in patient group; $14.37 \pm 4.01$ $\mathrm{mm}^{2}$ in control group, $\left.\mathrm{p}>0.05\right)$. On the other hand, flattening of the median nerve at the level of the hamate bone is also considered a positive finding. Because, the median nerve is maximally compressed at the level of the hamate bone in the CTS diagnosed patients (Radack et al., 1997; Andre et al., 1999).

When we compared the same parameter at the selected three levels of patient group with each other, there was a significant difference between distal radio-ulnar joint level and other specified two levels ( $\mathrm{p}<0.05)$. Measurements related to the median nerve are summarized in Table III. Such correlation, points at flattening of the median nerve which is a predisposant factor for CTS. The median nerve was examined in terms of interpositon since variable localizations were communiqued as another predisposant factor for CTS in some previous studies. The median nerve was imaged lying between the flexor pollicis longus muscle and flexor digitorum superficialis muscle interpositionally in five participants of the patient group in our study.

The intensity evaluation, showed hyperintensity in 28 of 36 wrist of the patient group and 8 were isointense; and hyperintensity in 7 of 34 controls and isointense in 27 . When we compared the incidence of hyperintensity, the result is statistically significant difference between patient and control groups (Table IV, p<0.05).

Table I. Numbers of positive and negative results in Phalen and Tinel test in patient and control groups (n: number of hands).

\begin{tabular}{lcccc}
\hline \multicolumn{1}{c}{ Groups } & Positive (n) & Negative (n) & Sensitivity & Specificity \\
\hline Patient group & 54 & 6 & $90 \%$ & - \\
Control group & 12 & 48 & - & $80 \%$ \\
\hline & \multicolumn{5}{c}{ Tinel test } & $70 \%$ & - \\
\hline Patient group & 42 & 18 & - & $76.6 \%$ \\
Control group & 14 & 46 & & \\
\hline
\end{tabular}

Table II. The comparison of cross-sectional area of the median nerve between CTS diagnosed patient and control groups at three levels (DRU: distal radio-ulnar, n: number of hands).

\begin{tabular}{cccc}
\hline $\begin{array}{c}\text { Cross-sec tional area of the median } \\
\text { nerve }\left(\mathrm{mm}_{-}\right)\end{array}$ & $\begin{array}{c}\text { Patient group } \\
(\text { Medium } \pm \text { SD }) \\
(\mathrm{n}=36)\end{array}$ & $\begin{array}{c}\text { Control group } \\
(\text { Medium } \pm \text { SD }) \\
(\mathrm{n}=34)\end{array}$ & $\mathrm{p}$ \\
\hline DRU joint level & $14.37 \pm 2.97$ & $11.62 \pm 2.01$ & $<0.005$ \\
Pisiform bone level & $15.94 \pm 3.05$ & $13.45 \pm 4.23$ & $<0.05$ \\
Hook of hamate bone level & $15.65 \pm 2.89$ & $14.37 \pm 4.01$ & $>0.05$ \\
\hline
\end{tabular}


Table III. The Comparison of cross-sectional area of the median nerve in CTS diagnosed patients group at three levels (DRU: distal radio-ulnar, n: number of hands).

\begin{tabular}{cccc}
\hline Paired samples t-Test & DRU joint level & Hook of hamate bone level & Pisiform bone level \\
\hline $\begin{array}{c}\text { DRU joint level } \\
\text { Hook of hamate bone level }\end{array}$ & Sig.(2-tailed) 0.038 $\mathrm{p}<0.05$ & Sig.(2-tailed) 0.038 p<0.05 & Sig.(2-tailed) 0.028 $\mathrm{p}<0.05$ \\
\hline
\end{tabular}

Table IV. The evaluation of signal intensity in CTS diagnosed patient and control groups (n: number of hands).

\begin{tabular}{cccc}
\hline Signal intensity in MRI & Patient group $(\mathrm{n}=36)$ & Control group $(\mathrm{n}=34)$ & Total $(\mathrm{n}=70)$ \\
\hline Hyperintensity & 28 & 8 & 36 \\
Isointensity & 7 & 27 & 34 \\
\hline
\end{tabular}

\section{DISCUSSION}

Carpal tunnel syndrome is a mostly chronic and sometimes disabling condition characterized by nocturnal pain, paresthesia of the fingers in the distribution of the median nerve, and in severe cases, thenar muscle hypotrophy caused by compression of the median nerve within the narrow carpal tunnel. Carpal tunnel syndrome usually occurs in adults, with a female predominance. The dominant hand is mostly affected but bilateral involvement is frequent (Hart \& Wibrg, 2001; Gelberman et al., 1981)

The underlying pathophysiology is thought to be mechanical distortion of the median nerve within the fibroosseus canal formed between the flexor retinaculum and the carpal bones at the wrist, a space also occupied by the superficial and deep flexor tendons of the fingers. Chronic compression or tethering of the median nerve is presumed to cause vascular compromise, as well as direct mechanical damage, first to the myelin and later to the axons of the nerve (Hart \& Wibrg; Lundborg \& Dahlin, 1996; Mackinnon, 1988). Clinical symptoms usually consist of tingling and numbness in a median nerve distribution, often worse at night and exacerbated by activity, combined with hand pain and weakness. Positive clinical signs consisting of a flick sign (shaking the hand to relieve symptoms), Tinel's sign (dysesthesias produced by tapping over the median nerve in the palm), and Phalen's sign (dysesthesias elicited by extreme wrist flexion) have sensitivities ranging from $20 \%$ to $70 \%$ and specificities ranging from $47 \%$ to $83 \%$ (D'Arcy \& McGee, 2000; Gellman et al., 1986; Katz et al., 1990; Stewart \& Eisen, 1978). In this study, sensitivity and specificity for the Phalen test were respectively 90 and $80 \%$ and for the Tinel test 70 and $76.6 \%$.

Studies of carpal tunnel syndrome have frequently combined males and females in a single subject group (Horch et al., 1997; Mesgarzadeh et al., 1989b; Seyfert et al., 1994;
Brahme et al.; Allmann et al.). Because of the lower incidence of carpal tunnel syndrome in males than in females (Hurst $e t$ al.; Phalen; Treaster \& Burr) no attempt was made in the present study to obtain a group of male patients with carpal tunnel syndrome. We assessed only females in the CTS diagnosed patient and control groups.

The use of MRI has been used frequently in dynamic examinations (Horch et al.; Yoshika et al., 1993) to evaluate canal diameter, and to perform postoperative patient assessments (Mesgarzadeh et al., 1995; Murphy et al., 1993) and painful wrist evaluations (Oneson et al., 1996; Healy et $a l ., 1990)$. Another reason to use MRI in patients with peripheral neuropathies is the potential to serve as an adjunct in the diagnosis and management of these patients (Weis et al., 1986; Britz et al., 1996; Grant et al.). A number of other studies have been published investigating the diagnostic accuracy of MRI for CTS (Pasternack et al., 2003; Horch et al.; Kleindienst et al., 1996; Kleindienst et al., 1998; Mesgarzadeh et al., 1989b; Murphy et al.; Oneson et al.; Pierre-Jerome et al., 1996a; Radack et al.; Soccetti et al., 1992; Timins et al., 1996). Our MRI protocols mainly focused on the assesment of morphologic anatomy of carpal tunnel and do not include functional MRI techniques. As we see the literature with regard to MRI of upper extremity peripheral neuropathies, most publications are also focused on the morphological appearance of those neuropathies (Jarvik et al., 2004; Beltran \& Rosenberg, 1994; Kim et al.; Spinner \& Amadio, 2003; Spratt et al.).

Many MR imaging reports have led to the establishment of the golden rule for the exclusive diagnosis of carpal tunnel syndrome, in which four criteria are considered. First, increased signal intensity of the median nerve on a fluidsensitive sequence is believed to be a sign of carpal tunnel syndrome, although a high signal intensity on STIR imaging 
is a normal finding, and the signal of the median nerve can be low when the symptom is chronic (Hochman \& Zilberfarb, 2004). Second, an increased size of the median nerve is considered a sign of carpal tunnel syndrome. The normal median nerve is flat at the level of the pisiform bone. Hence, enlargement of the median nerve is evaluated within the carpal tunnel at the level of the pisiform bone. Third, volar bowing of the flexor retinaculum at the level of the hamate bone is believed to demonstrate increased pressure in the carpal tunnel. Fourth, flattening of the median nerve at the level of the hamate bone is also considered a positive finding. These four MRI findings are now widely accepted, although they can be nonspecific and observed in asymptomatic individuals (Radack et al.).

Enlargement of the cross sectional area of the median nerve at the level of distal radio-ulnar joint and at the level of pisiform bone or at the entrance to the tunnel was found to be of diagnostic value for idiopathic CTS in the majority of cases studied (Martins et al., 2008; Uchiyama et al., 2005; Jarvik et al., 2002; Almann et al.; Mesgarzadeh et al., 1995; Monagle et al.; Kleindienst et al., 1996; Kleindienst et al., 1998). However, several investigators have shown a larger cross-sectional area of the nerve in CTS groups than in controls, even at the hook of the hamate bone level (Almann et al.; Mesgarzadeh et al., 1995; Monagle et al.). Mesgarzadeh et al. (1989b) presented the most distinct expansion at the level of the pisiform bone. This study has shown that the cross-sectional area of the median nerve both at the level of distal radio-ulnar joint and at the level of pisiform bone is larger in the CTS diagnosed patient group than control group, and there is statistically significant difference at these two anatomic level. An increase in crosssectional area of the median nerve was not found at the level of the hook of hamate bone. Although it is not statistically significant difference between patient and control groups. This is also considered a positive finding. It is widely accepted that median nerve to be expected flattening form (no enlargment) at the level of the hook of hamate bone in CTS diagnosed patients (Pasternack et al.; Cudlip et al., 2002; Bordalo Rodrigues et al., 2004; Radack et al.; Andre et al.). However, the flexor retinaculum is at its thickest at the level of the hook of hamate bone. Since the flexor retinaculum can be defenitely detected in this region and its borders can easily be followed, the most accurate evaluation can be made at this level. In addition, this level is a region where carpal tunnel apperently narrows and the median nerve is maximally compressed (Mesgarzadeh et al., 1989b; Soccetti et al.). And, we also found same clinical findings related to the median nerve at the level of the hook of hamate bone.

We observed a remarkable increase of intensity in the median nerve in $77.7 \%$ of the CTS patients when we evaluated the median nerve intensity. This rate was only $22.2 \%$ in the control group, and this difference between two groups was significant $(\mathrm{P}<0.05)$. Britz et al. demonstrated a signal increase in the median nerve in $95 \%$ of cases clinically diagnosed with CTS (Britz et al., 1995). The importance of the intensity increase in the median nerve in subclinical cases and during the early diagnosis of CTS has been emphasized (Dailey et al., 1997; Monagle et al.; Healy et al.; Kleindienst et al., 1998; Pierre-Jerome et al., 1996b), and this increase is believed to accompany cases which have already progressed clinically and electrophysiologically (Andre et al.; Zagnoli et al., 1999). Alman et al. observed that the intensity in the median nerve decreased in $67 \%$ of postoperative cases, and Mesgarzadeh et al. (1989a) emphasized that the importance of intensity increase in the medain nerve in the diagnosis of CTS. They also added that this expanded proximally towards the distal radio-ulnar joint same cases. In this study, we also determined that crosssectional area of the median nerve was increased at the level of distal radio-ulnar joint $(\mathrm{p}<0,005)$.

Enlargement of the median nerve area and signal intensity could be characteristic morphological findings for idiopathic CTS. Because of this, we evaluated that only spesific MRI findings, mostly cross-sectional area of the median nerve at the level of distal radioulnar joint, pisiform bone and the hook of hamate bone, showed to be closely correlated with some parameters obtained from previous studies and may become particulary the initiator of assessing idiopathic CTS.

\section{ACKNOWLEDGEMENTS}

The work was done at Department of Physical Medicine and Radiology, Özel Veni Vidi Hospital, and Department of Anatomy, Dicle University, Diyarbakır, Turkey. And, all authors thank Primal Pictures 3D Anatomy for using and designing the pictures related to the median nerve.

KARABULUT, Ö.; TUNCER, M. C.; KARABULUT, Z. \& GÜZEL, E. Análisis de imágenes de RM de las muñecas en pacientes mujeres con síndrome del túnel carpiano y controles sanos. Int. J. Morphol., 27(3):791-800, 2009.

RESUMEN: El objetivo de este estudio fue evaluar los cambios morfológicos del nervio mediano en pacientes con síndrome del túnel carpiano (STC) y controles sanos, para correlacionar los hallazgos de las RM de muñeca. Este estudio comparó no sólo los cambios morfológicos del nervio mediano, también se muestran en forma descriptiva estructuras del túnel carpiano entre los pacientes diagnosticados con STC idiopatico y controles sanos. 
Nuestro estudio incluyó 60 manos, 30 manos fueron evaluados con diagnóstico de STC idiopático y 30 manos como controles sanos, bilateralmente. Dos pruebas de provocación (prueba de Phalen y prueba de Tinel) se realizaron en cada mano para el grupo de pacientes (60 muñecas) y el grupo control (60 muñecas). En lo que respecta a los resultados de prueba de Phalen y prueba de Tinel, 24 y 26 muñecas fueron excluidas del grupo paciente y grupo control respectivamente. En total 70 muñecas fueron evaluadas, en términos de la sección transversal del área del nervio mediano a nivel de la articulación radio-ulnar distal, el hueso pisiforme y el hamulus del hueso hamate por medio de resonancia magnética en gruposs paciente y control. Además de la evaluación de la sección del área del nervio mediano, se determinó la intensidad de la señal de la muñeca y las diferentes localizaciones del nervio mediano en el túnel carpiano. La sección transversal del área del nervio mediano medida por medio de resonancia magnética de muñeca a nivel de los huesos metacarpianos y la intensidad de la señal de las muñecas pueden ser considerados como un valioso indicador al evaluar pacientes referidos con STC idiopático.

PALABRAS CLAVE: Imágen RM; Síndrome del túnel carpiano; Sección área transversal; Intensidad de señal; Nervio mediano.

\section{REFERENCES}

Adreisek, G.; Burg, D.; Studer, A.; Weishaupt, D. Upper extremity peripheral neuropathies: role and impact of MR imaging on patient management. Eur. Radiol., 18:1953-61, 2008.

Allmann, K. H.; Horch, R.; Uhl, M.; Gufler, H.; Altehoefer, C.; Stark, G. B. \& Langer, M. MR imaging of the carpal tunnel. Eur. J. Radiol., 25:141-5, 1997.

Amrami, K.; Felmlee, J. P. \& Spinner, R. J. MRI of peripheral nerves. Neurosurg. Clin. N. Am., 19:559-72, 2008.

Andre, V.; Zagnoli, F.; Andre, M.; Le Dreff, P.; Bellard, S.; \& Garcia, J. F. Clinical, electrophysiological and MRI correlation in carpal tunnel syndrome. Radiology, 80:721-6, 1999.

Beltran, J. \& Rosenberg, Z. S. Diagnosis of compressive and entrapment neuropathies of the upper extremity: value of MR imaging. AJR Am. J. Roentgenol., 163:52531, 1994.

Bone'1, H. M.; Heuck, A.; Frei, K. A.; Herrmann, K.; Scheidler, J.; Srivastav, S. \& Reiser, M. Carpal tunnel syndrome: assesment by turbo spin echo, spin echo, and magnetization transfer imaging applied in a low-field MR system. J. Comput. Assist. Tomogr., 25:137-45, 2001.
Bordalo Rodrigues, M.; Amin, P. \& Rosenberg, Z. S. MR imaging of common entrapment neuropathies at the wrist. Magn. Reson. Imaging Clin. N. Am., 12:265-79, 2004.

Brahme, K. S.; Hodler, J.; Braun, R. M.; Sebrechts, C.; Jackson, W. \& Resnick, D. Dynamic MR imaging of carpal tunnel syndrome. Skeletal Radiol., 26:482-7, 1997.

Britz, G. W.; Haynor, D. R.; Kuntz, C.; Goodkin, R.; Gitter, A. \& Kilot, M. Carpal tunnel syndrome: correlation magnetic resonance imaging, clinical, electrodiagnostic and intraoperative findings. Neurosurgery, 37:1097-103, 1995.

Britz, G. W.; Haynor, D. R.; Kuntz, C.; Goodkin, R.; Gitter, A.; Maravilla, K. \& Kliot, M. Ulnar nerve entrapment at the elbow: correlation ofmagnetic resonance imaging, clinical, electrodiagnostic, and intraoperative findings. Neurosurgery, 38:458-65, 1996.

Buchberger, W.; Judmaier, W.; Birbamer, G.; Lener, M. \& Schmidauer, C. Carpal tunnel syndrome: diagnosis with high-resoluation sonography. AJR, 159:793-8, 1992.

Cudlip, S. A.; Howe, F. A.; Clifton, A.; Schwartz, M. S. \& Bell, B. A. Magnetic resonance neurography studies of the median nerve before and after carpal tunnel decompression. J. Neurosurg., 96:1046-51, 2002.

Dailey, A. T.; Tsuruda, J. S.; Filler, A. G.; Maravilla, K. R.; Goodkin, R. \& Kliot, M. Magnetic resonance neurography of peripheral nerve degeneration and regeneration. Lancet, 350:1221-2, 1997.

D’Arcy, C. A. \& McGee, S. Clinical diagnosis of carpal tunnel syndrome. JAMA, 284:1924-5, 2000.

Deryani, E.; Aki, S.; Muslumanoglu, L. \& Rozanes, I. MR imaging and electrophysiological evaluation in carpal tunnel syndrome. Yonsei. Med. J., 44:27-32, 2003.

Gelberman, R. H.; Hergenroeder, P. T.; Hargens, A. R.; Lundborg, G. N. \& Akeson, W. H. The carpal tunnel syndrome. A study of canal pressures. Bone Joint Surg., 63:380-3, 1981.

Gellman, H.; Gelberman, R. H.; Tan, A. M. \& Botte, M. J. Carpal tunnel syndrome: an evaluation of the provocative diagnostic tests. J. Bone Joint Surg., 68:735-7, 1986.

Grant, G. A.; Britz, G. W.; Goodkin, R.; Jarvik, J. G.; Maravilla, K. \& Kliot, M. The utulity of magnetic resonance imaging in evaluating peripheral nerve disorders. Muscle Nerve, 25:314-31, 2001. 
Hart, A. M. \& Wibrg, M. Nerve compression or mechanical neuropathy: neuropathology. Curr. Orthopaed., 15:2458, 2001.

Healy, C.; Watson, J. D. \& Longstaff, A. A magnetic Resonance imaging of the carpal tunnel. J. Hand. Surg., 15:243-8, 1990.

Hochman, M. G. \& Zilberfarb, J. L. Nerves in a pinch: imaging of nerve compression syndromes. Radiol. Clin. North. Am., 42:221-45, 2004.

Hof, J.; Kliot, M.; Slimp, J. \& Haynor, D. R. What's new in MRI of peripheral nerve entrapment?. Neurosurg. Clin. N. Am., 19:583-95, 2008.

Horch, R. E.; Allmann, K. H.; Laubenberger, J.; Langer, M. \& Stark, G. B. Median nerve compression can be detected by magnetic resonance imaging of the carpal tunnel. Neurosurgery, 41:76-82, 1997.

Hurst, L. C.; Weissberg, D. \& Carroll, R. E. The relationship of the double crush to carpal tunnel syndrome (analysis of 1.000 cases of carpal tunnel syndrome). J. Hand. Surg., 10:202-4, 1985.

Jarvik, J. G.; Yuen, E.; Haynor, D. R.; Bradley, C. M.; FultonKehoe, D.; Smith-Weller, T.; Wu, R.; Kliot, M.; Kraft, G.; Wang, L.; Erlich, V.; Heagerty, P. J. \& Franklin, G. M. MR nerve imaging in a prospective cohort of patients with suspected carpal tunnel syndrome. Neurology, 58:1597-602, 2002.

Jarvik, J. G.; Yuen, E. \& Kliot, M. Diagnosis of carpal tunnel syndrome: electrodiagnostic and MR imaging evaluation. Neuroimaging Clin. N. Am., 14:93-102, 2004.

Katz, J. N.; Larson, M. G. \& Sabra, A. The carpal tunnel syndrome: diagnostic utility of the history and physical examination findings. Ann. Intern. Med., 112:321-7, 1990.

Keberle, M.; Jenett, M.; Kenn, W.; Reiners, K.; Peter, M.; Haerten, R. \& Hahn, D. Technical advances in ultrasound and MR imaging of carpal tunnel syndrome. Eur. Radiol., 10:1043-50, 2000.

Kim, S.; Choi, J. Y.; Huh, Y. M.; Song, H. T.; Lee, S. A.; Kim, S. M. \& Suh, J. S. Role of magnetic resonance imaging in entrapment and compressive neuropathywhat, where, and how to see the peripheral nerves on the musculoskeletal magnetic resonance image: part 2. Upper extremity. Eur. Radiol., 17:509-22, 2007.
Kleindienst, A.; Hamm, B.; Hildebrandt, G. \& Klug, N. Carpal tunnel syndrome: staging of median nerve compression by MR imaging. Acta. Neurochir., 138:22833, 1996.

Kleindiest, A.; Hamm, B. \& Lanksch, W. R. Carpal tunnel syndrome: stating of the median nerve compression by MR imaging. J. Magn. Reson. Imaging, 8:1119-25, 1998.

Lundborg, G. \& Dahlin, L. B. Anatomy, function, and pathophysiology of peripheral nerves and nerve compression. Hand. Clin., 12:185-93, 1996.

Mackinnon, S. E. Surgery of the peripheral nerve. New York, Thieme, 1988.

Martins, R. S.; Siqueira, M. G.; Simpl’1cio, H.; Agapito, D. \& Medeiros, M. Magnetic resonance imaging of idiopathic carpal tunnel syndrome: Correlation with clinical findings and electrophysiological investigation. Clin. Neurol. Neurosurg., 110:38-45, 2008.

Maurer, J.; Bleschkowski, A.; Tempka, A. \& Felix, R. High resolution MR imaging of the carpal tunnel and the wrist. Acta. Radiol., 41:78-83, 2000.

Mesgarzadeh, M. D.; Schneck, C. D. \& Bonakdarpour, A. Carpal tunnel: MR imaging. Normal anatomy. Radiology, 171:743-8, 1989a.

Mesgarzadeh, M. D.; Schneck, C. D.; Bonakdarpour, A.; Mitra, A.; Conaway, D. Carpal tunnel: MR imaging. II. Carpal tunnel syndrome. Radiology, 171:749-54, 1989b.

Mesgarzadeh, M. D.; Triolo, J. \& Schneck, C. D. Carpal tunnel syndrome. MR imaging diagnosis. Magn. Reson. Imaging Clin. North. Am., 3:249-64, 1995.

Middleton, W. D.; Kneeland, J. B.; Kellman, G. M.; Cates, J. D.; Sanger, J. R.; Jesmanowicz, A.; Froncisz, W. \& Hyde, J. S. MR imaging of the carpal tunnel: Normal anatomy and preliminary findings in the carpal tunnel syndrome. AJR, 148:307-16, 1987.

Monagle, K.; Dai, G.; Chu, A.; Burnham, R. S. \& Snyder, R. E. Quantitative MR imaging of carpal tunnel syndrome. AJR, 172:1581-6, 1999.

Murphy, R. X. Jr.; Chernofsky, M. A.; Osborne, M. A. \& Wolson, A. H. Magnetic Resonance imaging in the evaluation of the persistent carpal tunnel syndrome. $J$. Hand. Surg. Am., 18:113-20, 1993. 
Omer, G. E. Jr. Median nerve compression at the wrist. Hand. Clin., 8:317-24, 1992.

Oneson, S. R.; Scales, L. M.; Erickson, S. J. \& Timins, M. E. MR imaging of the painful wrist. Radiographics, 16:997-1008, 1996.

Pasternack, I. I.; Malmivaara, A.; Tervahartiala, P.; Forsberg, H. \& Vehmas, T. Magnetic resonans imaging findings in respect to carpal tunnel syndrome. Scand. J. Work Environ. Health, 29:189-96, 2003.

Phalen, G. S. The carpal tunnel syndrome: clinical evaluation of 598 hands. Clin. Orthop., 83:29-40, 1972.

Pierre-Jerome, C.; Bekkelund, S. I.; Husby, G.; Mellgren, S. I.; Osteaux, M. \& Nordstrom, R. MRI of anatomical variants of wrist in women. Surg. Radiol. Anat., 18:3741, 1996a.

Pierre-Jerome, C.; Bekkelund, S. I.; Mellgren, S. I. \& Torbergsen, T. Quantative magnetic resonance imaging and electrophysiology of the carpal tunnel region in flor cleaners. Scand. J. Work Environ. Health, 22:119-23, $1996 b$.

Propeck, T.; Quinn, T. J.; Jacobson, J. A.; Paulino, A. F. G.; Habra, G. \& Darian, V. B. Sonography and MR imaging of bifid median nerve with anatomic and histological correlation. AJR, 175:1721-5, 2000.

Radack, D. M.; Schweitzer, M. E. \& Taras, J. Carpal tunnel syndrome: are the MR findings a result of population selection bias?. AJR Am. J. Roentgenol., 169:1649-53, 1997.

Seyfert, S.; Boegner, F.; Hamm, B.; Kleindienst, A. \& Klau, C. The value of magnetic resonance imaging in carpal tunnel syndrome. J. Neumi., 242:41-6, 1994.

Sallomi, D.; Janzen, D. L.; Munk, P. L.; Connel, D. G. \& Tirman, P. F. Muscle denervation patterns in upper limb nerve injuries: MR imaging findings anatomic basis. AJR Am. J. Roentgenol., 171:77984, 1998.

Shuman, S.; Osterman, L. \& Bora, F. W. Compression neuropathies. Semin. Neurol., 7:76-87, 1987.

Soccetti, A.; Carloni, S.; Giovagnoni, M.; Ercolani, P.; Mercante, O. \& Pelliccioni, G. MR findings in post-traumatic carpal tunnel syndrome. Chir. Organi. Mov., 78:233-9, 1992.
Spinner, R. J. \& Amadio, P. C. Compressive neuropathies of the upper extremity. Clin. Plast. Surg., 30:155-73, 2003.

Spratt, J. D.; Stanley, A. J.; Grainger, A. J.; Hide, I. G. \& Campbell, R. S. The role of diagnostic radiology in compressive and entrapment neuropathies. Eur. Radiol., 12:2352-64, 2002.

Stewart, J. D. \& Eisen, A. Tinel's sign and the carpal tunnel syndrome. $B M J, 2: 1125-7,1978$.

Sugumito, H.; Miyaji, N. \& Ohsawa, T. Carpal tunnel syndrome: evaluation of median nerve circulation with dynamic contrast-enhanced MR imaging. Radiology, 190:459-66, 1994.

Timins, M. E.; O’Connell, S. E.; Erickson, S. J. \& Oneson, S. R. MR imaging of the wrist: normal findings that may simulate disease. Radiographics, 16:987-95, 1996.

Toussaint, C. \& Zager, E. L. What's new in common upper extremity entrapment neuropathies. Neurosurg. Clin. $N$. Am., 19:573-81, 2008.

Treaster, D. E. \& Burr, D. Gender differences in prevalence of upper extremity musculoskeletal disorders. Ergonomics, 47:495-526, 2004.

Uchiyama, S.; Itsubo, T.; Yasutomi, T.; Nakagawa, H.; Kamimura, M. \& Kato, H. Quantitative MRI of the wrist and nerve conduction studies in patients with idiopathic carpal tunnel syndrome. J. Neurol. Neurosurg. Psychiatry, 76:1103-8, 2005.

Weis, K. L.; Beltran, J. \& Shamon, O. M. High field MR surface coil imaging of the hand and wrist. Pathologic correlation and clinical relevance. Radiology, 160:14752,1986 .

Yoshika, S.; Okuda, Y.; Tamai, K.; Hirasawa, Y. \& Koda, Y. Changes in carpal tunnel shape during writs joint motion. MRI evaluation of normal volunteers. J. Hand. Surg., 18:620-3, 1993.

Zagnoli, F.; Andre, V.; Le Dreff, P.; Garcia, J. F. \& Bellard, S. Idiopathic carpal tunnel syndrome. Clinical, electrodiagnostic and magnetic resonance imaging correlation. Rev. Rhum. Engl., 66:192-200, 1999.

Zeiss, J.; Skie, M.; Ebraheim, N. \& Jackson, W. T. Anatomic relations between the median nerve and flexor tendons in the carpal tunnel: MR evaluation in normal volunteers. AJR Am. J. Roentgenol., 153:533-6, 1989. 
KARABULUT, Ö.; TUNCER, M. C.; KARABULUT, Z. \& GÜZEL, E. Analysis of MR imaging of wrists in female patients with carpal tunnel syndrome and healthy controls Int. J. Morphol., 27(3):791-800, 2009.

Zeiss, J.; Jakab, E.; Khimji, T. \& Imbriglia, J. The unlar tunnel at the wrist (Guyon's canal): normal MR anatomy and variants. AJR Am. J. Roentgenol., 158:1081-85, 1992.
Correspondence to:

Mehmet Cudi Tuncer

Department of Anatomy

Faculty of Medicine

Dicle University, 21280

Diyarbakır

TURKEY

Tel: +904122488001 Ext. 4539

Fax: +90 4122242083

Email: cudi@dicle.edu.tr

Received: 18-04-2009

Accepted: 27-05-2099 